\title{
Circulatory Heat Sources for Canine Respiratory Heat Exchange
}

\author{
Julian Solway, Alan R. Leff, Ismail Dreshaj, Nilda M. Munoz, Edward P. Ingenito, Daniel Michaels, \\ Roland H. Ingram, Jr., and Jeffrey M. Drazen \\ Department of Medicine and Committee on Clinical Pharmacology, The University of Chicago, Chicago, Illinois 60637; Departments of \\ Medicine, Brigham and Women's Hospital and Harvard Medical School, and Department of Environmental Science and Physiology, \\ Harvard School of Public Health, Boston, Massachusetts 02115
}

\begin{abstract}
We assessed the roles of the pulmonary and bronchial circulations as potential heat sources to the pulmonary airways during respiratory heat loss, by observing the changes in airstream temperature that accompanied temporary occlusion of the pulmonary or bronchial circulations. Baseline end-expiratory and end-inspiratory airstream temperatures were $35.4 \pm 0.2^{\circ} \mathrm{C}$ (SEM) and $30.9 \pm 0.3^{\circ} \mathrm{C}$, respectively, among all trials. With occlusion of the lower lobe pulmonary arteries for $3 \mathrm{~min}$ ipsilateral endexpiratory and end-inspiratory airstream temperatures fell by $2.8 \pm 0.2$ and $1.1 \pm 0.2^{\circ} \mathrm{C}$, respectively, during hyperpnea with room temperature air, and by $3.5 \pm 0.5$ and $1.8 \pm 0.2^{\circ} \mathrm{C}$, respectively, during hyperpnea with frigid air. In marked contrast, interruption of the bronchial circulation for $3 \mathrm{~min}$ had no effect on airstream temperatures. These data indicate that under these conditions, the pulmonary circulation, but not the bronchial circulation, serves as an important local heat source for respiratory heat exchange within the pulmonary airways.
\end{abstract}

\section{Introduction}

Respiratory heat and water loss have been shown to precipitate bronchoconstriction in asthmatic (1-5) subjects and, to a much lesser extent, in normal subjects (6). It is clear that the trachea and lower airways may participate in this warming and humidification of inspired air (7-10). Since the wall temperature of these pulmonary airways falls during hyperpnea $(10,11)$, it is conceivable that this change in mucosal temperature constitutes the stimulus for bronchoconstriction. Airway wall temperature reflects a balance between heat lost from the airways to the environment and heat supplied to the airways by body sources (12). Therefore, to understand how respiratory heat loss influences airway wall temperature, one must also know how the body replenishes heat to the airway wall. In this study, we examine the relative importances of the two potential circulatory heat sources for the airway wall: the bronchial arterial circulation and the pulmonary arterial circulation.

Although McFadden (12) has observed pallor of the human trachea during cold air hyperpnea by normal subjects, suggesting that mucosal blood flow might diminish in response to mucosal

Address correspondence to Dr. Solway, Section of Pulmonary and Critical Medicine, Department of Medicine, The University of Chicago, 5841 S. Maryland Ave., Chicago, IL 60637.

Received for publication 7 October 1985 and in revised form 12 May 1986.

J. Clin. Invest.

(c) The American Society for Clinical Investigation, Inc.

0021-9738/86/10/1015/05 $\$ 1.00$

Volume 78, October 1986, 1015-1019 cooling, Baile and colleagues (13) have recently reported that cold air hyperpnea in dogs results in increased blood flow in the tracheal and bronchial circulations. These authors suggested that this increase in blood flow might serve to blunt changes in intraairway temperature, but also noted that the total respiratory heat loss (2) observed in their experiments was greater than that which could have been provided by the tracheal and bronchial circulations alone.

We, too, reasoned that although the bronchial circulation is well positioned to influence airway wall temperature (14), the small magnitude of this blood supply ( $\sim 1 \%$ of the cardiac output [15]) might render its physiological role in affecting airway wall temperature insignificant. In contrast, the relatively large flow of blood (100\% of the cardiac output) within the pulmonary arteries, which remain adjacent to the bronchi as they branch, might act as a more effective heat source for airway wall warming. To characterize the sources of heat available to the pulmonary airways for respiratory heat exchange, we examined the changes in airstream temperature attending temporary interruption of the pulmonary and bronchial circulations in the dog. Our results indicate that the pulmonary, but not the bronchial circulation, acts as an important heat source for respiratory heat loss.

\section{Methods}

Nine adult mongrel dogs (body weight, $13.5-19.9 \mathrm{~kg}$ ) were anesthetized by intravenous administration of chloralose $(75 \mathrm{mg} / \mathrm{kg})$ and urethane ( $750 \mathrm{mg} / \mathrm{kg}$ ), with supplemental doses of $1 / 10$ the initial dose given hourly; no paralyzing agents were administered. Each animal was endotracheally intubated with a 9-10 $\mathrm{mm}$ i.d. cuffed endotracheal tube; the endotracheal tube tip was positioned just beneath the glottis, except as described below. Balloon-tipped catheters were passed into one or both lower lobe pulmonary arteries (LLPA), 'through an external jugular vein. Their positions were confirmed with a fluoroscope in the first five animals studied; the characteristic changes of ipsilateral airstream temperature, which consistently accompanied balloon inflation (see below), was used to identify balloon location in subsequent animals.

To measure airstream temperature, we manufactured catheters containing copper-constantan thermocouples made of 40-gauge wire, with time constants of $60 \mathrm{~ms}$ in air flowing at a linear velocity of $40 \mathrm{~cm} / \mathrm{s}$. Thermocouple wires were passed through PE-240 tubing; the thermocouple junction was positioned in the center of a 4-5-mm diameter, 10$\mathrm{mm}$ length wire cage (Fig. 1) similar to that described by Primiano et al. (16). These instruments were passed through the endotracheal tube into the right and left lower lobes, and were positioned under bronchoscopic guidance into 4-5-mm diameter airways 7-13 cm distal to the main carina. The cage configuration ensured that the thermocouple junctions remained near the center stream of airflow, and the relatively small size of the catheter relative to the airway lumen (cross-sections

1. Abbreviations used in this paper: BEA, bronchoesophageal artery; ICA, intercostal arteries; LLPA, lower lobe pulmonary arteries; PA, pulmonary artery. 


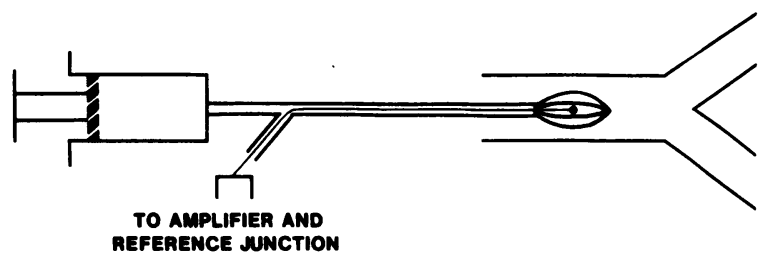

Figure 1. Schematic diagram of the intraairway temperature probe employed in these experiments. The syringe at the external end of the catheter could be used to blow secretions off the thermocouple junction and cage when they occasionally lodged there.

$\sim 4.6 \mathrm{~mm}^{2}$ and $15.9 \mathrm{~mm}^{2}$, respectively), ensured minor, if any, interference with the physiologic distribution of airflow. This instrumentation yielded reproducible temperature fluctuations within each animal during respiration. Occasional lodging of airway secretions on a thermocouple junction resulted in slowing of its temperature response; this event was easily recognized as a change from an asymmetric temperature vs. time signal to a sawtooth pattern with diminished fluctuation amplitude (Fig. 2), and such data were discarded; the junction was cleaned and data were collected again.

During data collection, each animal was mechanically ventilated at hyperpneic levels with a volume-cycled ventilator (Harvard Apparatus Co., Inc., S. Natick, MA) using tidal volumes of $410 \pm 100 \mathrm{ml}$ at $55 \pm 7$ breaths/min (minute ventilation, $18-28$ liters $/ \mathrm{min}$ ) with dry $5 \% \mathrm{CO}_{2}$ in air from a compressed gas tank. Inspired gas was delivered at room temperature, or was cooled to subfreezing temperature $\left(\sim-10^{\circ} \mathrm{C}\right)$ by passage through a refrigeration device (1). Tidal volume was recorded using a volume-displacement body plethysmograph (when frigid air was inspired) or by integrating the flow signal from a pneumotachograph (model 2; Fleisch) coupled to a pressure transducer (model 15 ETC; Statham) placed at the airway opening (when air at room temperature was inspired). Core temperature, estimated using a rectal probe, was maintained at $36.8 \pm 2.8^{\circ} \mathrm{C}$ with a heating pad.

The influence of blood flow within the pulmonary circulation on local airstream temperatures was assessed in the following way: Each animal was mechanically ventilated with large minute volumes as described above for $3 \mathrm{~min}$; airstream temperatures reached steady endinspiratory and end-expiratory values within this period. While continuing hyperpnea, blood flow within one LLPA was temporarily interrupted by inflation of its catheter balloon; airstream temperature changes were recorded for the following $3 \mathrm{~min}$, during which new steady temperature fluctuations were usually reached, though in some instances temperatures were still decreasing at the end of this period. Thereafter, the balloon was deflated and airstream temperatures were recorded for another 3 $\mathrm{min}$. The airstream temperatures reported here are those recorded within the final $15 \mathrm{~s}$ of each period.

In four animals, the influence of blood flow within the bronchial circulation on local airstream temperatures was assessed by temporary
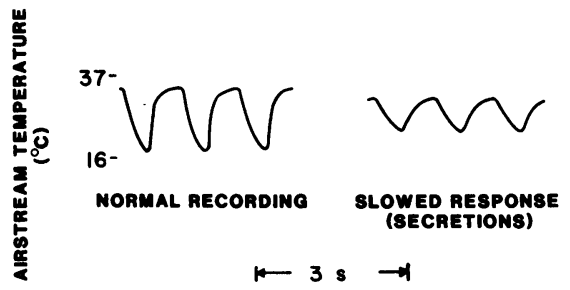

Figure 2. Typical airstream vs. time pattern during hyperpnea. Left, a normal thermocouple response; right, a slowed response induced by lodging of secretions on the thermocouple junction. These tracings were obtained in the trachea and demonstrate larger airstream temperature fluctuations than were recorded within the lower lobes. interruption of bronchial artery blood flow in the following way. A right thoracotomy was performed in the sixth and eighth intercostal spaces. The right lung was retracted, and the azygous vein was dissected, exposing the underlying intercostal arteries. Remotely activated vascular clamps were positioned loosely around the common bronchoesophageal artery (BEA), or around nine to eleven right intercostal arteries (ICA) near their origins, always including the fifth, sixth, seventh, and eighth intercostal arteries. In one experiment, the right first through fifth ICAs were ligated, and the sixth ICA (from which the BEA arose) was isolated with a vascular clamp. In another experiment, a left thoracotomy was also performed, and all 11 left ICAs plus left and right internal thoracic arteries were ligated before transient right ICA occlusion. After isolation of these major sources of the bronchial blood supply (17), the chest was closed loosely with clamps, and the lungs were reinflated with $3-5 \mathrm{~cm} \mathrm{H}_{2} \mathrm{O}$ positive end-expiratory pressure. In three animals, the endotracheal tube was advanced to within 3-6 cm of the main carina to minimize the influence of a persistent tracheal circulation on heat and water transport.

In these experiments, as in those assessing the importance of LLPA blood flow, local airstream temperatures were measured during the last $15 \mathrm{~s}$ of 3-min periods of hyperpnea before, during, and after cessation of interruption of the bronchial circulation by temporary clamping and release of the BEA or right ICAs. In all, eight such experiments were performed. In three additional experiments, this sequence was performed while one LLPA balloon was inflated throughout. After completing the above protocols, in three animals the BEA was cannulated with PE-50 tubing (18). Airstream temperatures were then measured during hyperpnea before, during, and after infusion of iced saline into the BEA at $\sim 30 \mathrm{ml} / \mathrm{min}$ (at least three times the expected bronchial blood flow rate). Inspired gas was always at room temperature in these bronchial circulation experiments.

Paired data were compared using Student's $t$ test for paired data. A $P$ value of $<0.05$ was considered significant.

\section{Results}

Baseline end-expiratory and end-inspiratory airstream temperatures obtained during hyperpnea, before occlusions of the pulmonary or bronchial circulations were $35.4 \pm 0.2$ and $30.9 \pm 0.3^{\circ} \mathrm{C}$ (SEM), respectively, among all trials. Right and left airstream end-inspiratory and end-expiratory temperatures were approximately equal (Table I). ${ }^{2}$

Fig. 3 illustrates the typical effects of unilateral LLPA occlusion during isocapnic hyperpnea. Ipsilateral airstream temperatures fall over at least $3 \mathrm{~min}$, but contralateral airstream temperatures remain largely unchanged. Baseline preocclusion temperatures are rapidly reestablished after deflation of the obstructing LLPA balloon. After $3 \mathrm{~min}$ of LLPA occlusion, ipsilateral end-inspiratory and end-expiratory airstream temperatures decreased from preocclusion values by $2.8 \pm 0.2$ ( $P$ $<0.0001)$ and $1.1 \pm 0.2^{\circ} \mathrm{C}(P<0.0001)(\mathrm{SEM})$, respectively, during hyperpnea with air at room temperature, and by $3.5 \pm 0.5$ $(P<0.002)$ and $1.8 \pm 0.2^{\circ} \mathrm{C}(P<0.0005)(\mathrm{SEM})$, respectively, during hyperpnea with frigid air (Fig. 4). Ipsilateral airstream temperatures returned almost completely to preocclusion values within 1-2 min of LLPA reperfusion; reperfusion airstream temperatures were $0.1 \pm 0.0^{\circ} \mathrm{C}(P<0.02)$ below preocclusion values. Contralateral end-inspiratory and end-expiratory airstream temperatures remained almost unchanged during LLPA

2. Note that the influence of inspired gas temperature on airstream temperature was not an objective of the current study, and that other factors (i.e., thermocouple location, minute ventilation, etc.) were not held constant among frigid and room temperature trials. 
Table I. Baseline Airstream Temperatures

\begin{tabular}{llllll}
\hline & \multicolumn{2}{l}{ End-inspiratory } & & \multicolumn{2}{l}{ End-expiratory } \\
\cline { 2 - 3 } \cline { 5 - 6 } & \multicolumn{2}{l}{ Inspired gas temperature } & & \\
\cline { 2 - 3 } & Room & Frigid & Room & Frigid \\
\hline Right lower lobe & $30.4 \pm 0.4$ & $30.8 \pm 1.0$ & $35.3 \pm 0.3$ & $35.5 \pm 1.0$ \\
Left lower lobe & $31.8 \pm 0.5$ & $29.7 \pm 1.6$ & $35.5 \pm 0.4$ & $35.1 \pm 1.0$
\end{tabular}

Entries are airstream temperatures ( \pm SEM) in degrees Celsius. $n=14$ for room air trials; $n=4$ (right lower lobe) or $n=5$ (left lower lobe) for frigid air trials.

occlusion (mean falls of $0.0 \pm 0.1[P>0.6]$ and $0.4 \pm 0.1^{\circ} \mathrm{C}[P$ $<0.01$ ] [SEM], respectively).

In marked contrast, interruption of the bronchial circulation for $3 \mathrm{~min}$ had virtually no effect on airstream temperatures. The largest fall of any end-inspired or end-expired airstream temperature was $0.4^{\circ} \mathrm{C}$, and among all temperature measurements there was $<0.1^{\circ} \mathrm{C}$ mean change from preinterruption values $(P$ $>0.7$ ). In an effort to reduce the potential for the pulmonary circulation to mask airstream temperature changes that might otherwise become apparent upon interrupting the bronchial circulation, we measured airstream temperatures during simultaneous occlusion of the bronchial and pulmonary circulations in three experiments (Fig. 5). Although ipsilateral airstream temperatures decreased in all cases with LLPA occlusion, there was minimal, if any, further change with superimposed interruption of the bronchial circulation.

In three dogs in which the common bronchoesophageal artery was cannulated, infusion of iced saline at $\sim 30 \mathrm{ml} / \mathrm{min}$ resulted in a dramatic fall in airstream temperature during hyperpnea (Fig. 6); substantially greater decreases were seen in airstream temperature within the right lower lobe than within the left lower lobe. We did not perfuse the pulmonary circulation with iced saline.

\section{Discussion}

A recent study by Baile and colleagues (13) demonstrates that cold air hyperpnea increases blood flow within the bronchial circulation of the dog. Given that the intrapulmonary airways participate in the warming of cold inspired air $(9,10)$, this result suggests the presence of a homeostatic mechanism designed to maintain airway wall temperature. We reasoned that although the bronchial arteries are well positioned to provide heat to the airway wall (19) during conditions of respiratory heat loss, the diminutive magnitude of the blood flow within these vessels might obviate their ability to provide much heat to the bronchi.

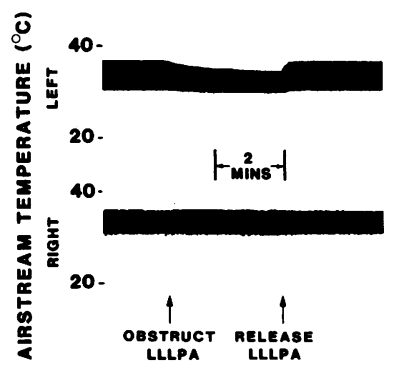

Figure 3. Influence of left lower lobe pulmonary artery (LLLPA) occlusion on airstream temperatures in right and left lower lobes during isocapnic hyperpnea.
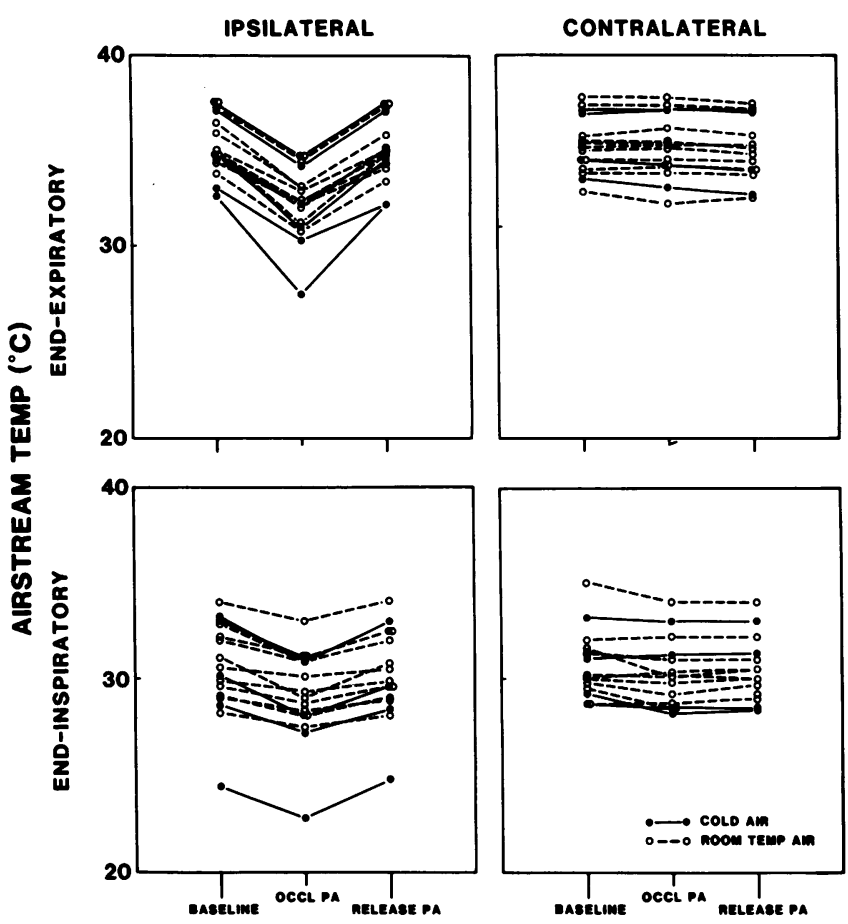

Figure 4. Influence of unilateral LLPA occlusion on ipsilateral and contralateral airstream temperatures during hyperpnea of room temperature or frigid air as indicated.

By contrast, the entire cardiac output flows through the pulmonary arteries, which remain adjacent to the bronchi as both branch along the respiratory tree (20). We thought it likely that these vessels might provide heat to the airways by lateral conduction from pulmonary artery to adjacent airway wall. Our results indicate that the pulmonary circulation, rather than the bronchial circulation, plays the more important role in reducing airway wall cooling in the dog during hyperpnea of cold and/or dry air.

Note that the changes in airstream temperature observed in our study during temporary vascular occlusion reflect concommitant changes in airway wall temperature. Although it is well established that flow regime, breathing pattern, and inspired air conditions $(1-6,9-12,21)$ can each influence airstream temperature, these were all maintained constant during temporary vascular occlusion. Since alveolar gas temperature undoubtedly remained at body core temperature during these studies, the only other way for exhaled gas temperature to have fallen during vascular occlusion is for the airway wall to have cooled. Thus,

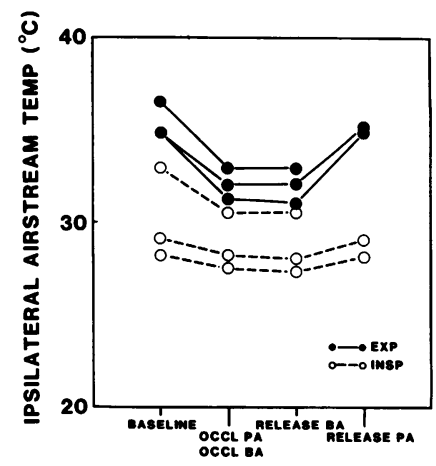

Figure 5. Airstream temperature changes during occlusion of the bronchial arterial (BA) circulation in the presence of ipsilateral lower lobe pulmonary artery (PA) obstruction during hyperpnea of room temperature air. 


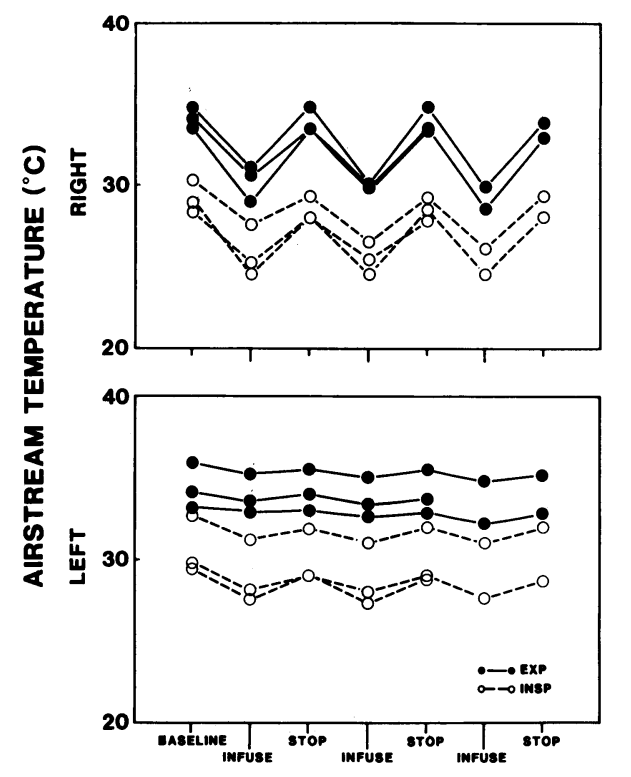

Figure 6. Influence of infusion of iced saline into the common bronchoesophageal artery on end-expiratory airstream temperatures during hyperpnea of room temperature air.

in our experiments, a transient fall in airstream temperature indicated a transient fall in airway wall temperature. A fall in end-inspiratory temperature reflected less heat transfer to inspired air by the cooler airway walls during inspiration, and a fall in end-expiratory temperature reflected greater recovery of heat from alveolar gas (presumably at body temperature in the alveoli) by the cooler airway walls during expiration $(10,12$, 21). Conversely, when airstream temperature did not change, there was no change in airway wall temperature.

In each of our dogs, obstruction of one of the lower lobe pulmonary arteries (LLPA) reduced airstream temperatures in the ipsilateral lower lobe airways, but had little if any effect on contralateral airstream temperatures. This result demonstrates that the alteration in heat transfer from LLPA to the airways was a local, rather than global, phenomenon. Because contralateral temperatures did not change, we cannot ascribe our results to reduction of cardiac output or other systemic changes that might have accompanied inflation of the LLPA balloon. It also seems unlikely that LLPA obstruction caused decreased blood flow within the bronchial circulation. These vessels anastomose at the level of the alveolar bed (22); Baile et al. (23) have shown that when alveolar capillary pressure is increased by positive end-expiratory pressure, bronchial arterial flow decreases. It seems probable that reduction of local alveolar capillary pressure by LLPA obstruction should have increased bronchial blood flow, if any change indeed occurred. Therefore, we can conclude that the fall in local airstream temperatures that accompanied local LLPA obstruction reflected diminished heat transfer from the LLPA to the airway wall.

To identify the level at which this heat transfer from LLPA to airway wall occurs, we performed an additional experiment in which we measured blood temperature within the left LLPA (with a thermocouple junction positioned $1.5 \mathrm{~cm}$ distal to the tip of the balloon catheter) as well as left lower lobe airstream temperature before, during, and after obstruction of blood flow within the LLPA. As shown in Fig. 7, blood temperature within the obstructed LLPA fell by $3.0^{\circ} \mathrm{C}$ at the end of $2 \frac{1 / 3}{\mathrm{~min}}$ of cold

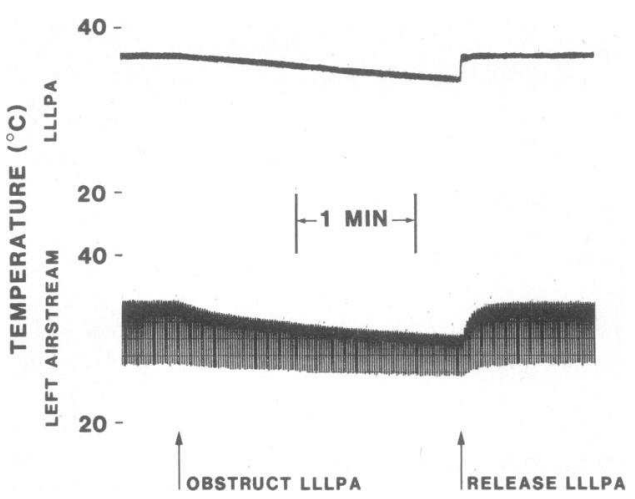

Figure 7. Simultaneous recording of left lower lobe airstream temperature and left lower lobe pulmonary artery (LLLPA) blood temperature during cold air hyperpnea; the LLLPA was transiently occluded as indicated.

air hyperpnea; with release of the LLPA obstruction, blood temperature increased rapidly as blood at body temperature replaced the chilled stagnant LLPA blood. This observation confirms that heat is transferred from pulmonary artery to airway wall; there are two potential routes for this heat flow: $(a)$ Heat transfers from pulmonary artery (PA) blood to alveolar gas in distal lung regions. Were this the case, occlusion of the PA could conceivably decrease alveolar gas temperature, and decrease the rewarming of airway walls (cooled during inspiration) during exhalation. The decrease in PA blood temperature that we observed during occlusion would have to be explained by conduction of heat from central PA blood along the stagnant PA blood stream down a temperature gradient to the alveolar capillary blood. (b) Heat transfers from pulmonary artery blood to the airway wall by lateral conduction through the tissues which separate them (PA wall, connective tissue). The decrease in PA blood temperature that we observed would be explained by conduction of heat to the adjacent airway wall down a temperature gradient between these two structures.

We think that the latter possibility is the more likely. As shown in Fig. 7 , there was a $2.2^{\circ} \mathrm{C}$ temperature difference between the PA blood and end expiratory gas in the absence of PA occlusion; the difference between PA and local airway wall temperatures must be at least as great (21). Since the thermal conductance of the tissues between these structures is probably close to that of blood, the proximity of the central PA to its adjacent airway wall would favor heat flow directly from the PA to the adjacent airway wall rather than along the longer route (a) described above. Thus, it appears that lateral heat conduction from pulmonary arteries to the adjacent bronchi plays a physiologically important role in warming the walls of large bronchi. One obvious physiological advantage of the adjacent anatomic arrangement of branching pulmonary arteries and airways is that it minimizes cooling of airway walls during hyperpnea.

In contrast, we found no fall in airstream temperatures when the bronchial circulation was transiently interrupted (Fig. 5). Baile et al. (13) have recently demonstrated that even though blood flow within the bronchial circulation of dogs increases during cold air hyperpnea, it is still of diminutive magnitude $(0.37 \%$ of the cardiac output). The ability of the bronchial circulation to act as an effective heat source at body temperature depends on a relatively rapid replacement of cooled blood by fresh blood at body temperature. Since flow within the bronchial 
circulation is but a small fraction of that within the pulmonary circulation, it is not surprising that the bronchial circulation is less effective at heating airway walls than is the pulmonary circulation, despite its more optimal location investing the airway walls (24).

It is conceivable that one reason we found no effect of obstructing the bronchial circulation is that we failed to diminish bronchial blood flow substantially with our vascular clamps; we think this an unlikely possibility. First, we clamped most or all of the major systemic arterial sources for the bronchial circulation, including the common BEA and the right intercostal arteries (17), and in one dog we also ligated the left intercostal arteries as well as both internal thoracic arteries near the thoracic outlet (17). Although it is possible that retrograde flow from the pulmonary circulation provided blood to the bronchial circulation during its occlusion, we saw no airstream temperature changes when the bronchial circulation was obstructed in the presence of simultaneous LLPA occlusion (Fig. 5). Second, we think that it is unlikely that we misidentified the bronchoesophageal artery. Upon cannulating this vessel and infusing iced saline at $30 \mathrm{ml} / \mathrm{min}$ (at least three times greater flow than the intact bronchial circulation [13]), we found that airstream temperatures did drop (Fig. 6) by an amount similar to that seen with pulmonary artery occlusion. Thus, only under these nonphysiologic conditions was the bronchial circulation capable of influencing airway wall temperatures. Under physiologic circumstances the bronchial circulation seems unimportant in heating airway walls, at least by comparison to the pulmonary circulation.

It is unlikely that our intraairway temperature probes substantially influenced our results. First, the cross-sectional area of the catheter was small compared with that of the airway into which it was positioned, so that the physiological distribution of ventilation was likely unaltered. In addition, the wire cage ensured that the thermocouple junction remained in approximately the center stream of flow, avoiding inadvertant contact with the airway wall. Second, we compared right and left airstream temperatures; identical catheters were placed into each airway, and any potential alteration of physiological conditions should have been similar in both loci.

In summary, we have shown that during hyperpnea, the pulmonary circulation of the dog, but not its bronchial circulation, functions as a physiologically important heat source for central airway walls. This heat transfer from pulmonary arteries probably occurs at least by lateral conduction between adjacent vessel and bronchus, and represents a heretofore unappreciated feature of the functional anatomy of the lung.

\section{Acknowledgments}

This work was supported by National Heart, Lung, and Blood Institute grants HL34702, HL33009, HL01398, and HL32495, and by the Parker B. Francis Fellowship of the Puritan-Bennett Foundation.

\section{References}

1. Deal, E. C., E. R. McFadden, Jr., R. H. Ingram, Jr., and J. J. Jaeger. 1979. Hyperpnea and heat flux: initial reaction sequence in exercise-induced asthma. J. Appl. Physiol. Respir. Environ. Exercise Physiol. 46(3):476-483.

2. Zeballos, R. J., R. Shturman-Ellstein, J. F. McNally, Jr., J. E. Hirsch, and J. F. Souhrada. 1978. The role of hyperventilation in exerciseinduced bronchoconstriction. Am. Rev. Respir. Dis. 118:877-884.

3. Anderson, S. D., R. E. Schoeffel, R. Follet, C. P. Perry, E. Daviskas, and M. Kendall. 1982. Sensitivity to heat and water loss at rest and during exercise in asthmatic patients. Eur. J. Respir. Dis. 63:459-471.

4. Higenbottam, T., T. Stokes, S. Jamieson, and L. Hill. 1983. A comparison of exercise, hyperventilation with cold air and warm air, and the inhalation of "fog" in the provocation of asthma. Eur. J. Respir. Dis. 64:421-423.

5. Chen, W. Y., and D. J. Horton. 1977. Heat and water loss from the airways and exercise-induced asthma. Respiration 34:305-313.

6. O'Cain, C. F., N. B. Dowling, A. S. Slutsky, M. J. Hensley, K. P. Strohl, E. R. McFadden, Jr., and R. H. Ingram, Jr. 1980. Airway effects of respiratory heat loss in normal subjects. J. Appl. Physiol. Respir. Environ. Exercise Physiol. 49(5):875-880.

7. Man, S. F. P., G. K. Adams, and D. F. Proctor. 1979. Effects of temperature, relative humidity, and mode of breathing on canine airway secretions. J. Appl. Physiol. Respir. Environ. Exercise Physiol. 46(2): 205-210.

8. Boucher, R. C., M. J. Stutts, P. A. Bromberg, and J. T. Gatzy. 1981. Regional differences in airway surface liquid composition. J. Appl. Physiol. Respir. Environ. Exercise Physiol. 50(3):613-620.

9. McFadden, E. R., Jr., D. M. Denison, Jr., J. F. Waller, B. Assoufi, A. Peacock, and T. Sopwith. 1982. Direct recordings of the temperatures in the tracheobronchial tree in normal man. J. Clin. Invest. 69:700-705.

10. McFadden, E. R., Jr., B. M. Pichurko, H. F. Bowman, E. Ingenito, S. Burns, N. Dowling, and J. Solway. 1985. Thermal mapping of the airways in humans. J. Appl. Physiol. 58:564-570.

11. Deal, C. D.; Jr., E. R. McFadden, Jr., R. H. Ingram, Jr., and J. J. Jaeger. 1979. Esophageal temperature during exercise in asthmatic and nonasthmatic subjects. J. Appl. Physiol. 46(3):484-490.

12. McFadden, E. R., Jr. Respiratory heat and water exchange: physiological and clinical implications. 1983. J. Appl. Physiol. Respir. Environ. Exercise Physiol. 54(2):331-336.

13. Baile, E. M., R. W. Dahlby, B. R. Wiggs, and P. D. Pare. 1985. Role of tracheal and bronchial circulation in respiratory heat exchange. J. Appl. Physiol. 58:217-222.

14. Solway, J., I. Dreshaj, E. Ingenito, R. H. Ingram, Jr., and J. M. Drazen. 1985. Circulatory heat sources for respiratory heat exchange. Am. Rev. Respir. Dis. 131(4, Part 2):319A. (Abstr.)

15. Baile, E. M., J. M. B. Nelems, M. Schulzer, and P. D. Pare. 1982. Measurement of regional bronchial arterial blood flow and bronchovascular resistance in dogs. J. Appl. Physiol. Respir. Environ. Exercise Physiol. 53(4):1044-1049.

16. Primiano, F. P., Jr., F. W. Montague, Jr., and G. M. Saidel. 1984. Measurement system for respiratory water vapor and temperature dynamics. J. Appl. Physiol. Respir. Environ. Exercise Physiol. 56(6):16791685.

17. Evans, H. E., and G. C. Christensen. 1979. Miller's Anatomy of the Dog. 2nd ed. W. B. Saunders Co., Philadelphia.

18. Hendrix, S. G., N. M. Munoz, and A. R. Leff. 1983. Physiological and pharmacological response of canine bronchial smooth muscle in situ. J. Appl. Physiol. Respir. Environ. Exercise Physiol. 54(1):215-224.

19. Daly, I. D. B., and C. Hebb. 1966. Bronchial vascular system. In Pulmonary and Bronchial Vascular Systems. Chapter 2. Williams \& Wilkins, Baltimore.

20. Daly, I. D. B., and C. Hebb. 1966. Bronchial vascular system. In Pulmonary and Bronchial Vascular Systems. Chapter 1. Williams \& Wilkins, Baltimore.

21. Solway, J., B. M. Pichurko, E. P. Ingenito, E. R. McFadden, Jr., C. H. Fanta, R. H. Ingram, Jr., and J. M. Drazen. 1985. Breathing pattern affects airway wall temperature during cold air hyperpnea. Am. Rev. Respir. Dis. 132:853-857.

22. Modell, H. I., K. Beck, and J. Butler. 1981. Functional aspects of canine bronchial-pulmonary vascular communications. J. Appl. Physiol. Respir. Environ. Exercise Physiol. 50(5):1045-1051.

23. Baile, E. M., R. K. Albert, W. Kirk, S. Lakshaminarayan, B. J. R. Wiggs, and P. D. Pare. 1984. Positive end-expiratory pressure decreases bronchial blood flow in the dog. J. Appl. Physiol. Respir. Environ. Exercise Physiol. 56:1289-1293.

24. Miller, W. S. 1947. The Lung. Thomas, Springfield, IL., 69-83. 